\title{
ENDOVASCULAR STENT IMPLANTATION FOR THE MANAGEMENT OF POSTOPERATIVE RIGHT VENTRICULAR OUTFLOW TRACT OBSTRUCTION: CLINICAL EFFICACY
}

Caroline Ovaert, MD

Christopher A. Caldarone, $\mathrm{MD}^{\mathrm{b}}$

Brian W. McCrindle, MD, FRCPC, FACC ${ }^{a}$

David Nykanen, MD, FRCPC ${ }^{a}$

Robert M. Freedom, MD, FRCPC, FACC ${ }^{a}$

J. G. Coles, MD, FRCS ${ }^{\text {b }}$

W. G. Williams, MD, FRCS ${ }^{\text {b }}$

Lee N. Benson, MD, FRCPC, FACC, FSCAI ${ }^{\mathrm{a}}$
Objective: Extracardiac conduits between the right ventricle and pulmonary arteries commit patients to multiple reoperations. We reviewed our experience with stent implantation in obstructed conduits. Methods: Between 1990 and 1997, stents were implanted across 43 conduits. The median age at procedure was 6 years (0.5-17 years), and the median interval between conduit insertion and stent implantation was 2.4 years (0.3-14 years). Results: Mean systolic right ventricular pressures and gradients, respectively, decreased from $71 \pm 18 \mathrm{~mm} \mathrm{Hg}$ and $48 \pm 19 \mathrm{~mm} \mathrm{Hg}$ before to $48 \pm 15 \mathrm{~mm} \mathrm{Hg}$ and $19 \pm 13 \mathrm{~mm} \mathrm{Hg}$ after stent placement. Mean percentage of predicted valve area for body surface area increased from $26 \% \pm 12 \%$ to $48 \% \pm 17 \%$ after stent placement. Fifteen patients underwent a second transcatheter intervention (dilation or additional stent), and 2 patients, a third, allowing further postponement of surgery in 8 patients. One sudden death occurred 2.8 years after stent placement. Surgical conduit replacement has occurred in 20 patients. Body growth was maintained during follow-up. Freedom from surgical reintervention was $86 \%$ at 1 year, $72 \%$ at 2 years, and $47 \%$ at 4 years. Higher right ventricular pressure and gradient before and after stent placement and lower percentage of predicted valve area for body surface area after stent placement were associated with shorter palliation. Conclusion: Endovascular stent placement across obstructed conduits is a safe and effective palliation that allows for normal body growth. (J Thorac Cardiovasc Surg 1999;118:886-93)
$T^{\mathrm{h}}$ he placement of extracardiac conduits between the pulmonary ventricle and the pulmonary arteries has allowed the correction of many complex cardiac lesions. ${ }^{1,2}$ These techniques, however, almost always commit the patient to multiple surgical reinterventions because of progressive obstruction within the conduit. ${ }^{1-5}$ The cause for these progressive obstructive lesions include both conduit and valve deterioration, and the simple fact that small children eventually outgrow the initially placed conduit. ${ }^{3,5}$ Previous studies

From the Departments of Pediatrics and Surgery, Divisions of Cardiology $^{\mathrm{a}}$ and Cardiovascular Surgery, ${ }^{\mathrm{b}}$ and the Variety Club Cardiac Catheterization Laboratories, The Hospital for Sick Children, The University of Toronto School of Medicine, Toronto, Ontario, Canada.

Received for publication Feb 9, 1999; revisions requested April 13, 1999; revisions received June 7, 1999; accepted for publication Aug 24, 1999.

Address for reprints: Lee N. Benson, MD, The Hospital for Sick Children, 555 University Ave, Toronto, Ontario, Canada M5G 1X8 (E-mail: benson@ sickkids.on.ca).

Copyright $\odot 1999$ by Mosby, Inc.

0022-5223/99 $\$ 8.00+0 \quad \mathbf{1 2 / 1 / 1 0 2 4 7 4}$ have demonstrated that percutaneous implantation of balloon expandable stents offer a safe and effective palliation for obstructed conduits. ${ }^{6-9}$ In the present study, we further report our experience with this palliative strategy and its impact on clinical management.

\section{Methods}

Patient selection. Since 1990, the option of transcatheter endovascular stent implantation within the right ventricular outflow tract has been offered for patients with right ventricle-to-pulmonary artery conduits when surgical replacement was considered necessary for management of significant obstruction. Right ventricular pressure exceeding two thirds of systemic arterial pressure, as observed on echocardiography, was considered an indication for intervention, with or without the presence of symptoms such as effort intolerance or fatigue.

Technique. The technique of implantation has been described in detail in a previous report. ${ }^{6}$ Balloon-expandable stent implants (Palmaz type; Johnson \& Johnson Interventional Systems, Warren, NJ), available in different lengths $(\mathrm{P} 128=12 \mathrm{~mm}, \mathrm{P} 188=18 \mathrm{~mm}, \mathrm{P} 204=20 \mathrm{~mm}, \mathrm{P} 308=30$ $\mathrm{mm}, \mathrm{P} 4014=40 \mathrm{~mm}$, and P5015 = $50 \mathrm{~mm}$ ), were used, depending on the diameter and length of the obstruction. 
Several minor modifications of the original approach have been incorporated into our present technique. After angiographic and hemodynamic characterization of the obstructive lesion at cardiac catheterization, the sheath covering the balloon stent is now inserted as a single unit over an exchange wire from femoral vascular access, improving placement in the tight curve of the right ventricular outflow tract. Prior balloon dilation of the conduit is not performed unless the conduit appears to be heavily calcified. For this study, informed parental consent was obtained before all procedures.

Follow-up assessment. In the early cohort, a cross-sectional and Doppler echocardiogram was performed within 48 hours after stent placement. This echocardiogram was less systematically obtained in the latter portion of the series. After hospital discharge, patients were assessed in the outpatient clinic on a regular basis, as clinically indicated (usually every 6 months), typically with assessments being made by means of cross-sectional and Doppler echocardiography. When feasible, the pressure gradient across the right ventricular outflow tract, the right ventricular pressures (when tricuspid regurgitation was detectable), and the ventricular enddiastolic dimensions were estimated. A chest radiograph was obtained when indicated. Repeat cardiac catheterization was often performed after 1 year, as part of the regular follow-up in the early experience. Later in our experience, cardiac catheterization was typically performed when the echocardiogram suggested the presence of a significant recurrent obstruction (right ventricular pressures greater than $66 \%$ of systemic arterial pressure).

\section{Data collection}

Initial cardiac catheterization. Hemodynamic data, including pressures in the right ventricle and in the main pulmonary artery, as well as calculation of the ratio of right ventricle to systemic blood pressure, were recorded before and after stent implantation. On angiography, the type of conduit stenosis was classified as "subvalvar," "valvar," "supravalvar," "diffusely small," or "calcified." The minimal dimension of the conduit was measured in the anteroposterior and lateral angiographic projections, allowing estimation of a minimal area. The formula used for the area was based on the assumption that the conduit geometry was ellipsoid (Area $=\pi \mathrm{ab}$, where $a$ and $b$ are the orthogonal minimal dimensions). This estimate was made from angiography before and after stent implantation. The cross-sectional area was expressed as a percentage of the predicted pulmonary valve orifice area corrected for body surface area. ${ }^{6,10}$ Immediate complications of the procedure, technical difficulties, and the fluoroscopy time were noted.

Follow-up data. Echocardiographic data (right ventricular pressures and end-diastolic dimensions) and the ratio of right ventricular to systemic blood pressure assessed immediately before and after stent implantation, at latest follow-up or before surgical conduit replacement, were recorded. The right ventricular end-diastolic dimensions were expressed as $z$ scores, normalized to body size. Cardiothoracic ratios were measured from radiographs. For patients who underwent repeat catheter interventions, procedural details and hemody- namic and echocardiographic data before and after repeat catheterization were also recorded.

Data analysis. Patient and procedural characteristics are described as frequencies, medians with ranges, and means with standard deviations as appropriate. Where there were missing data, the number of non-missing values are reported for that variable. All statistical analyses were performed by using SAS Version 6.12 statistical software (SAS Institute, Inc., Cary, NC) with default settings. Changes in hemodynamic parameters and vascular dimensions were tested with paired $t$ tests. Outcomes during follow-up were described, and estimates of freedom from surgical conduit replacement were plotted by using Kaplan-Meier curves. The effect of patient and procedural characteristics and acute results on freedom from surgical conduit replacement were each tested in Cox's proportional hazard regression modeling. A probability value of less than 0.05 was set as the level of statistical significance.

\section{Results}

Patient characteristics. Between July 1990 and May 1997, 42 patients underwent transcatheter insertion of endovascular stents for relief of obstruction in a right ventricle-to-pulmonary artery conduit. One patient underwent a second procedure in a new conduit after surgical replacement of a previously stented conduit. Twenty-four patients were men $(57 \%)$ and 18 were women $(43 \%)$. Underlying cardiac diagnoses consisted of pulmonary atresia with ventricular septal defect in 16 patients $(38 \%)$, Fallot's tetralogy in 10 patients $(24 \%)$, truncus arteriosus in 7 patients $(17 \%)$, transposition of the great arteries with ventricular septal defect in 5 patients (12\%), double outlet right ventricle in 3 patients (7\%), and aortic valve stenosis managed with a Ross procedure in 1 patient (2\%).

For the remainder of the analysis, the unit of measurement was the 43 episodes of initial stent implantation, with the 1 patient who had 2 consecutive conduits and stent implantations counted twice. Twenty-seven patients $(63 \%)$ had undergone at least 1 cardiac operation before the conduit insertion, and 13 patients (30\%) had had their conduits replaced at least once before endovascular stent placement. The conduits in place at the time of endovascular stent implantation were pulmonary homografts in 13 procedures (30\%), aortic homografts in $11(26 \%)$, Polystan valved conduits in $11(26 \%)$, conduits with Symbion or Hancock porcine valves placed in the orthotopic position in 4 and 1 , respectively (11\%), a monocusp patch in a pulmonary homograft in $1(2 \%)$, and simple enlargement with a patch in a previously inserted pulmonary homograft in 2 procedures $(5 \%)$.

The median age at the time of the procedure was 6 
Table I. Hemodynamic and angiographic results at transcatheter endovascular stent implantation

\begin{tabular}{lccc}
\hline & Before stent & After stent & P value \\
\hline RV systolic pressure (mm Hg) & $71 \pm 18(\mathrm{n}=43)$ & $48 \pm 15(\mathrm{n}=43)$ & $<.001(\mathrm{n}=43)$ \\
Ratio of RV to systemic arterial systolic pressure & $0.76 \pm 0.21(\mathrm{n}=43)$ & $0.46 \pm 0.12(\mathrm{n}=39)$ & $<.001(\mathrm{n}=38)$ \\
RVOT peak to peak systolic gradient (mm Hg) & $48 \pm 19(\mathrm{n}=40)$ & $19 \pm 13(\mathrm{n}=33)$ & $<.001(\mathrm{n}=31)$ \\
PA pressure (mm Hg) & $23 \pm 7(\mathrm{n}=40)$ & $27 \pm 8(\mathrm{n}=33)$ & $0.002(\mathrm{n}=31)$ \\
Minimal diameter conduit in AP view (mm) & $7.1 \pm 1.8(\mathrm{n}=34)$ & $9.4 \pm 1.9(\mathrm{n}=39)$ & $<.001(\mathrm{n}=34)$ \\
Minimal diameter conduit in LAT view (mm) & $6.6 \pm 2.2(\mathrm{n}=39)$ & $9.4 \pm 2.1(\mathrm{n}=41)$ & $<.001(\mathrm{n}=39)$ \\
\% of predicted minimal PV area for BSA (\%) & $26 \pm 12(\mathrm{n}=31)$ & $48 \pm 17(\mathrm{n}=38)$ & $<.001(\mathrm{n}=31)$ \\
\hline
\end{tabular}

$A P$ view, Anteroposterior angiographic projection; $B S A$, body surface area; $L A T$ view, lateral angiographic projection, $P A$, pulmonary artery; $R V$, right ventricle; $R V O T$, right ventricular outflow tract; $P V$, pulmonary valve.

* From paired $t$ tests.

Table II. Echocardiographic variables before and after transcatheter stent implantation

\begin{tabular}{lccc}
\hline & Before stent & After stent & P value* \\
\hline Estimated RV systolic pressure (mm Hg) & $70 \pm 11(\mathrm{n}=25)$ & $50 \pm 12(\mathrm{n}=27)$ & $<.001(\mathrm{n}=20)$ \\
Ratio of RV to systemic systolic pressure & $0.75 \pm 0.16(\mathrm{n}=16)$ & $0.55 \pm 0.11(\mathrm{n}=7)$ & $.09(\mathrm{n}=4)$ \\
RVOT peak to peak systolic gradient $(\mathrm{mm} \mathrm{Hg})$ & $63 \pm 17(\mathrm{n}=39)$ & $38 \pm 17(\mathrm{n}=34)$ & $<.001(\mathrm{n}=33)$ \\
\hline
\end{tabular}

$R V$, Right ventricle; $R V O T$, right ventricular outflow tract.

* From paired $t$ tests.

years (range, 0.5 to 17 years), with a median interval between conduit insertion and endovascular stent placement of 2.4 years (range, 0.3 to 14 years). The median weight at time of the procedure was $19 \mathrm{~kg}$ (range, 6.5 to $58 \mathrm{~kg}$ ), and median height $(\mathrm{n}=38)$ was $110 \mathrm{~cm}$ (range, 63 to $167 \mathrm{~cm}$ ). Symptoms were noted before the procedure in 11 patients $(26 \%)$, and these included increased fatigue, reduced exercise tolerance, and chest pain. One patient with a ventricular septal defect had increasing cyanosis. For all patients, the echocardiographic data and the hemodynamic data at the time of cardiac catheterization indicated the need for intervention.

\section{Initial procedure}

Type of stenosis. Angiographically, conduit stenosis was subvalvar in 1 patient (2\%), valvar in $23(54 \%)$, supravalvar in 5 (12\%), combined valvar and supravalvar in $9(21 \%)$, and diffuse (small conduit) in 5 (12\%). Extensive calcification within the conduit wall was present in 5 patients $(12 \%)$.

Procedure. Of the 43 procedures, 38 patients had 1 stent inserted within the conduit, 4 patients had 2 stents placed, and 1 patient had 3 stents. The length of the implants were $12 \mathrm{~mm}$ in 1 patient (2\%), $18 \mathrm{~mm}$ in 2 (5\%), $20 \mathrm{~mm}$ in $9(20 \%), 30 \mathrm{~mm}$ in $28(65 \%), 40 \mathrm{~mm}$ in $2(5 \%)$, and $50 \mathrm{~mm}$ in 1 patient $(2 \%)$. The median maximal balloon diameters used for stent dilation was $15 \mathrm{~mm}$ (range, 8 to $20 \mathrm{~cm}$ ). Larger diameter balloons were often used at the end of the procedure to flare the ends of the stents. Mean fluoroscopy time for the procedure $(n=42)$ was $40 \pm 25$ minutes.
The stent covered the valve of the conduit in all but 1 patient, in whom the stent was just above the valvar ring but kept the leaflets in an open position. The presence of subvalvar stenosis (at the junction between the conduit and the right ventricle), isolated in 1 patient and associated with other locations of stenosis in 5 other patients, did not complicated the procedure and did not necessitate modifications of the technique.

Hemodynamic and angiographic data. Hemodynamic and angiographic data before and after stent placement, expressed as mean values \pm 1 standard deviation, are shown in Table I.

Mean percentage changes in hemodynamic parameters were noted as follows: right ventricular systolic pressure, $-30 \% \pm 21 \%(P<.001)$; ratio of right ventricle to systemic arterial systolic pressure, $-36 \% \pm 17 \%$ (n $=38, P<.001)$; and right ventricle to pulmonary artery systolic gradients, $-60 \% \pm 20 \%(\mathrm{n}=31, P<$ $.001)$. Pulmonary artery systolic pressures increased slightly, but significantly, with a mean percentage change of $+27 \% \pm 37 \%(\mathrm{n}=31, P<.001)$.

The minimal diameter of the conduit increased significantly after implantation, with a mean percentage change of $+36 \% \pm 33 \%(\mathrm{n}=34, P<.001)$ in the anteroposterior view and $+51 \% \pm 44 \%(\mathrm{n}=39, P<$ .001 ) in the lateral view. Mean percentage increase for the percent of predicted pulmonary valve cross-sectional area for body size was $+133 \% \pm 107 \%(\mathrm{n}=31$, $P<.001 ;$ Table I).

Echocardiographic data. The data from echocardio- 
Table III. Hemodynamic and angiographic results at transcatheter reintervention

\begin{tabular}{lccc}
\hline & Before & After & P value \\
\hline Hemodynamic data & & & \\
RV systolic pressure (mm Hg) & $66 \pm 15(\mathrm{n}=15)$ & $52 \pm 11(\mathrm{n}=13)$ & $.002(\mathrm{n}=13)$ \\
Ratio of RV to systemic arterial systolic pressure & $0.7 \pm 0.1(\mathrm{n}=12)$ & $0.5 \pm 0.2(\mathrm{n}=12)$ & $.007(\mathrm{n}=11)$ \\
$\quad$ RVOT peak to peak systolic pressure gradient (mm Hg) & $40 \pm 18(\mathrm{n}=11)$ & $20 \pm 7(\mathrm{n}=9)$ & $.03(\mathrm{n}=6)$ \\
Echocardiographic data & & & $*$ \\
$\quad$ Estimated RV systolic pressure (mm Hg) & $57 \pm 17(\mathrm{n}=9)$ & $71 \pm 15 \mathrm{~mm} \mathrm{Hg}(\mathrm{n}=5)$ & $*$ \\
$\quad$ Doppler peak instantaneous RVOT systolic gradient & $53 \pm 19 \mathrm{~mm} \mathrm{Hg}(\mathrm{n}=10)$ & $54 \pm 14 \mathrm{~mm} \mathrm{Hg}(\mathrm{n}=7)$ & \\
$\quad$ & & & $*$ \\
\hline
\end{tabular}

$R V$, Right ventricle; $R V O T$, right ventricular outflow tract.

* Insufficient data to perform statistical analysis.

Table IV. Echocardiographic parameters at latest follow-up assessment in patients with and without subsequent conduit replacement

\begin{tabular}{lcc}
\hline & No surgery $(n=23)$ & Surgery $(n=20)$ \\
\hline Estimated RV systolic pressure (mm Hg) & $53 \pm 14(\mathrm{n}=12)$ & $73 \pm 12(\mathrm{n}=9)$ \\
Ratio of RV to systemic arterial systolic pressure & $0.55 \pm 0.13(\mathrm{n}=9)$ & .003 \\
RVOT Doppler peak instantaneous systolic gradient & $39 \pm 19(\mathrm{n}=20)$ & .03 \\
$\quad(\mathrm{~mm} \mathrm{Hg})$ & & $.002 \pm 21(\mathrm{n}=13)$ \\
\hline
\end{tabular}

$R V$, Right ventricle; $R V O T$, right ventricular outflow tract.

grams, obtained at a median of 2.6 months (range, 1 day to 8.3 years) before $(n=42)$ and a median of 1 day (range, $<1$ day to 10.8 months) after $(\mathrm{n}=39)$ the stent implantation, are shown in Table II.

Mean percentage changes in hemodynamic parameters from echocardiograms before and after stent implantation were noted as follows: right ventricular pressure estimated by tricuspid insufficiency, $-24 \% \pm$ $24 \%$ (n $=20, P<.001$ ); ratio of right ventricle to systemic arterial systolic pressure, $-39 \% \pm 24 \%(\mathrm{n}=4, P$ $<.05$ ); and Doppler peak instantaneous gradient across the right ventricular outflow tract, $-37 \% \pm 29 \%(\mathrm{n}=33$, $P<.001)$.

Early complications. In 1 patient, the stent migrated distally during placement, and a second stent was implanted across the obstruction. In 1 patient, there was interference with the catheter course from the femoral vein because of the presence of a permanent pacing wire, and this necessitated vascular access from the neck. In 2 patients, the stent partially covered the origin of one or both pulmonary artery orifices, but further dilation of the distal end of the stent avoided obstruction. In 1 patient, a stenosis persisted at the distal end of the stent and a second stent was implanted, but the balloon ruptured such that full expansion of the stent was not possible. The stent was withdrawn and implanted in the inferior caval vein. In 2 additional patients, the balloon ruptured during inflation, necessitating balloon catheter exchange. In 3 patients, posi- tioning or opening of the stent was suboptimal, leaving a residual stenosis. The majority of technical difficulties were encountered during the first 3 years of the reported experience.

Transcatheter reintervention. Fifteen patients had a second and 2 patients had a third transcatheter intervention after the initial implantation. The second intervention was performed at a median of 1 year (range, 2.2 months to 2.6 years) after the initial stent implantation procedure. In 12 of these patients, the previously implanted stent was dilated, and in 3 patients an additional stent was implanted. The median balloon diameter used was $15 \mathrm{~mm}$ (range, 8 to $18 \mathrm{~mm}$ ). The median duration of fluoroscopy $(\mathrm{n}=13)$ was 30 minutes (range, 10 to 118 minutes).

The hemodynamic data obtained at catheterization and the echocardiographic data from before and after reintervention are shown in Table III. Mean percentage changes in hemodynamic parameters were noted as follows: right ventricular systolic pressure, $-19 \% \pm 15 \%$ (n $=13, P<.001)$; ratio of right ventricle to systemic arterial systolic pressure, $-22 \% \pm 19 \%(\mathrm{n}=11, P=$ $.004)$; and right ventricle to pulmonary artery peak to peak systolic pressure gradients, $-34 \% \pm 31 \%(\mathrm{n}=6, P$ $<.05)$. There were inadequate numbers to allow statistical analysis of echocardiographic data.

In two reintervention procedures, technical difficulties occurred. At 1 procedure, the balloon ruptured as it was inflating within a previously implanted stent, and a 


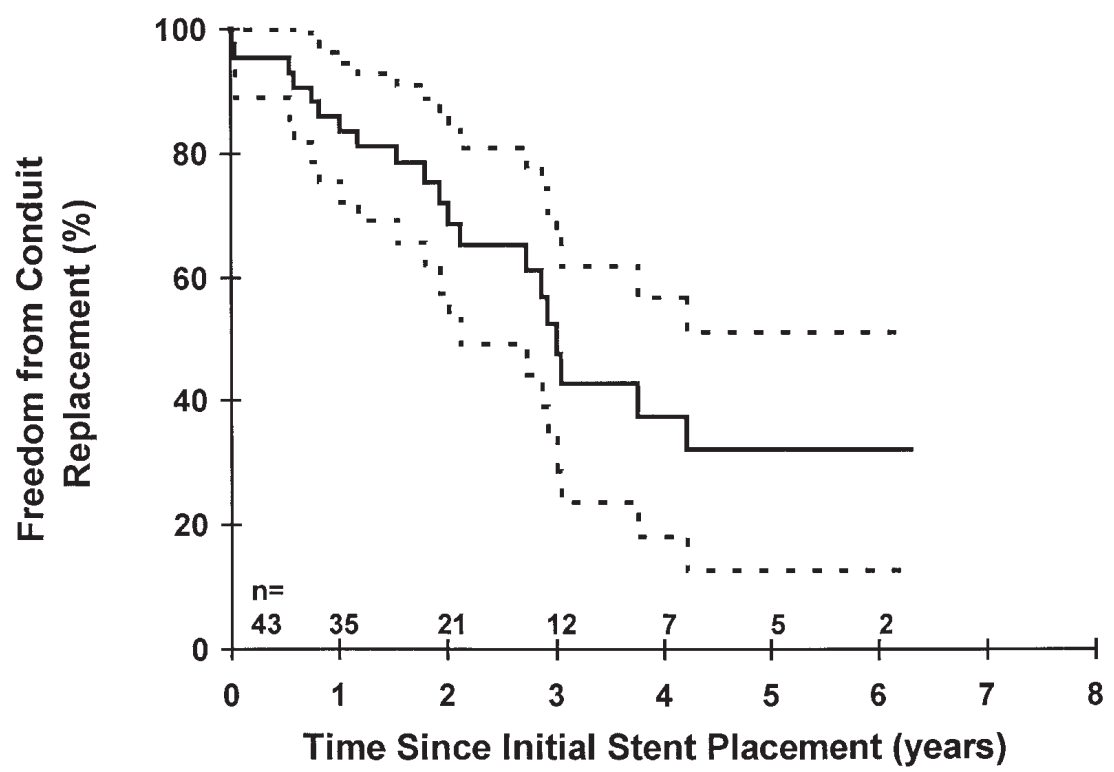

Fig 1. Kaplan Meier plot of freedom from conduit replacement after transcatheter endovascular stent implantation. Dashed lines, $95 \%$ confidence interval.

second balloon could not enlarge the stent further. In another patient, the previously implanted stent slipped to the right pulmonary artery. A second stent was then prepared, the delivery sheath exposed the stent prematurely, and the stent was deployed into the iliac vein. A third stent was implanted, but during balloon inflation the balloon ruptured, and it was not possible to fully enlarge the stent.

Of these 15 reintervention procedures, 8 (53\%) were successful in reducing right ventricular systolic pressures or increasing systemic oxygen saturations (1 patient with open ventricular septal defect), allowing further postponement of surgical intervention. In 2 patients a third transcatheter reintervention was attempted with stent dilation. However, both procedures were unsuccessful in further decreasing right ventricular systolic pressures.

Late follow-up and surgical reintervention. One late sudden death occurred 2.8 years after initial stent implantation. The patient died at home, and no autopsy was performed, leaving the question of the cause of death unanswered.

Over the course of our reported experience, surgical conduit replacement was performed in 20 patients. Indication for conduit replacement in those patients was the presence of right ventricular pressures above two thirds of systemic arterial pressure as noted on echocardiography. Conduit replacement was uneventful in those 20 patients, and no surgical difficulties or compli- cations related to the presence of the stents were reported. The median follow-up interval for the remaining 22 patients was 2.2 years (range, 9.6 months to 6 years).

Body growth was maintained during the follow-up period, with a median weight increase $(n=34)$ of $4 \mathrm{~kg}$ (range, -0.6 to $22 \mathrm{~kg}$ ) and a median height increase $(\mathrm{n}=$ 30) of $11 \mathrm{~cm}$ (range, 0 to $34 \mathrm{~cm}$ ). Mean weight velocity $(\mathrm{n}=34)$ was $+2.6 \pm 2.2 \mathrm{~kg}$ per year of follow-up, with a mean height velocity $(\mathrm{n}=30)$ of $+6.3 \pm 4.1 \mathrm{~cm} / \mathrm{y}$.

For those patients who have not had surgical replacement of their conduits $(n=23)$, the latest echocardiographic assessment showed a mean estimated right ventricular systolic pressure $(\mathrm{n}=12)$ of $53 \pm 14 \mathrm{~mm}$ $\mathrm{Hg}$, a mean ratio of right ventricle to systemic arterial systolic pressure $(n=9)$ of $0.55 \pm 0.13 \mathrm{~mm} \mathrm{Hg}$, and a mean Doppler peak instantaneous right ventricular outflow tract gradient $(\mathrm{n}=20)$ of $39 \pm 19 \mathrm{~mm} \mathrm{Hg}$. Table IV compares the echocardiographic data at latest follow-up for the patients with and without surgical conduit replacement.

To determine the effect of transcatheter intervention on ventricular dilation, right ventricular end-diastolic dimensions assessed at echocardiography were converted to $z$ scores on the basis of patient age (unpublished normative data from our echocardiographic laboratory) and compared. Comparison of $z$ values of right ventricular end-diastolic dimension at echocardiographic assessment just before stent implantation ( $\mathrm{n}=$ $33,+5.7 \pm 4.3, P<.001$ vs normal) and at the latest 
Table V. Factors at initial transcatheter stent implantation associated with time to conduit replacement*

\begin{tabular}{|c|c|c|c|c|}
\hline & $n$ & $\begin{array}{l}\beta \text { Coefficient } \\
\text { (standard error) }\end{array}$ & $\mathrm{P}$ value & $R R(95 \% C I)$ \\
\hline \multicolumn{5}{|l|}{ Pre-implantation } \\
\hline Age at conduit insertion $(\mathrm{y})$ & 43 & $0.0611(0.0825)$ & .5 & $1.06(0.90,1.46)$ \\
\hline Age at stent implantation (y) & 43 & $-0.0106(0.0541)$ & .8 & $0.99(0.89,1.10)$ \\
\hline Interval from conduit insertion to stent implantation (y) & 43 & $-0.1273(0.1135)$ & .3 & $0.88(0.70,1.10)$ \\
\hline Weight (kg) & 43 & $0.0039(0.0185)$ & .8 & $1.00(0.97,1.04)$ \\
\hline Right ventricle systolic pressure $(\mathrm{mm} \mathrm{Hg})$ & 43 & $0.0356(0.0141)$ & .02 & $1.04(1.01,1.07)$ \\
\hline Ratio of RV to systemic arterial systolic pressure & 43 & $1.6637(1.1558)$ & .15 & $5.28(0.55,50.9)$ \\
\hline Gradient from RV to PA (mm Hg) & 40 & $0.0277(0.0140)$ & $<.05$ & $1.03(1.00,1.06)$ \\
\hline $\begin{array}{l}\text { Percentage of predicted cross-sectional area of minimal } \\
\text { conduit dimension }\end{array}$ & 31 & $-0.0154(0.0284)$ & .6 & $0.99(0.93,1.04)$ \\
\hline Ratio of balloon to minimal conduit diameter & 40 & $-2.1798(1.4747)$ & .14 & $0.11(0.02,2.04)$ \\
\hline \multicolumn{5}{|l|}{ Post-implantation } \\
\hline Right ventricle systolic pressure (mm Hg) & 43 & $0.0581(0.0182)$ & .002 & $1.06(1.02,1.10)$ \\
\hline Ratio of RV to systemic arterial systolic pressure & 39 & $2.3491(1.6945)$ & .17 & $10.5(0.38,290)$ \\
\hline Gradient from RV to PA (mm Hg) & 33 & $0.0735(0.0251)$ & .004 & $1.08(1.02,1.13)$ \\
\hline $\begin{array}{l}\text { Percentage of predicted cross-sectional area of minimal } \\
\text { conduit dimension }\end{array}$ & 38 & $-0.0611(0.0228)$ & .008 & $0.94(0.90,0.98)$ \\
\hline
\end{tabular}

$P A$, Pulmonary artery; $R R$, risk ratio; $R V$, right ventricle.

* From univariable Cox's proportionate hazard regression modeling.

echocardiographic assessment before conduit replacement or at latest follow-up $(\mathrm{n}=30,+6.1 \pm 3.5, P<.001$ vs normal) did not show any significant changes $(\mathrm{n}=$ $26, P=.48$ ). Likewise, comparison of the mean cardiothoracic ratios from chest radiographs before stent implantation $(\mathrm{n}=32,0.58 \pm 0.06)$ and before surgical conduit replacement or at latest follow-up $(n=27,0.58$ $\pm 0.04)$ did not reveal any significant changes $(n=27$, $P=.68)$.

Freedom from conduit replacement. Kaplan-Meier analysis revealed a freedom from conduit replacement of $86 \%$ at 1 year, $72 \%$ at 2 years, and $47 \%$ at 4 years after initial transcatheter stent implantation (Fig 1). Cox's proportionate hazard regression modeling was used to test the effect of individual variables on time to conduit replacement (Table V). In univariable analysis, a decreased time to conduit replacement (ie, decreased duration of palliation with stent implantation) was significantly associated with a higher right ventricular systolic pressure and a higher right ventricular outflow tract peak to peak systolic gradient both before and after initial stent implantation, and a lower percentage of predicted cross-sectional area of minimal conduit dimension after stent implantation. In stepwise variable selection, only a lower percentage of predicted crosssectional area of minimal conduit dimension after stent implantation was independently associated with a reduced time to conduit replacement; after controlling for this variable, no other variable could be entered significantly into the final model.

\section{Discussion}

Over the last 30 years, the use of extracardiac valved conduits between the subpulmonary ventricle and the pulmonary arteries has allowed for correction of a number of complex congenital heart lesions. Despite various technical modifications and the availability of different types of valved conduits, this technique still commits the patients to multiple operations. A recent report published by Stark and colleagues, ${ }^{2}$ reviewing 405 conduits implanted between 1971 and 1993, describes an overall conduit survival at 5, 10, and 15 years of $84 \%, 58 \%$, and $31 \%$, respectively, with conduit obstruction being the most frequent reason for surgical reintervention. ${ }^{2,5}$ Hemodynamic and immunologic mechanisms may be responsible for calcification and deterioration occurring at various levels or diffusely throughout the conduit. ${ }^{3,5}$ Indeed, in Stark's recent study, second and subsequent conduits had shorter survival than the original implants. The authors hypothesized that adhesions and calcifications present at reoperation made it more difficult to obtain an ideal fit and flow characteristics at replacement. ${ }^{2}$ Thus, even if conduit replacement is considered a low-risk intervention, techniques to prolong conduit survival should be explored.

In our study, all patients required intervention on the basis of clinical, echocardiographic, or hemodynamic findings. While stenosis can occur at multiple locations within the course of the conduit-making Doppler echocardiographic assessment difficult, and at times misleading — several clinical studies have shown a 
good correlation between gradients obtained by continuous-wave Doppler echocardiography and those obtained at cardiac catheterization. ${ }^{11,12}$ However, in vitro studies have demonstrated that the combination of decreasing tunnel cross-sectional area with increasing tunnel length may lead to significant underestimation of pressure gradients by Doppler echocardiographic assessment. ${ }^{13}$ With these limitations in mind, analysis of right ventricular systolic pressures by means of the peak velocity of the tricuspid valve regurgitation jet has, in our experience, been the preferred method of assessing the presence and progression of conduit obstruction. In this series, angiography showed the conduit stenosis to be mainly at valvar and supravalvar levels (at the site of the anastomosis with the pulmonary arteries), similar to previous data. ${ }^{3}$ Such discrete valvar or supravalvar stenoses respond well to stent implantation, as contrasted with a diffusely small conduit.

Despite earlier reports showing some relief of conduit stenosis with transcatheter balloon angioplasty alone, ${ }^{14,15}$ subsequent reports have noted a high incidence of failure of balloon dilation in these cases, compared with other types of right heart obstructions. ${ }^{16,17}$ In an attempt to confer a reliable enlargement to such stenotic lesions, Almagor and associates ${ }^{9}$ were the first to deploy a stent across a stenotic right heart valved conduit in baboons. Subsequent clinical studies have shown that stent implantation could effectively relieve conduit stenosis and postpone surgical conduit replacement. ${ }^{6-8,18}$ Our study confirms these previous data, with a freedom from surgical replacement of $47 \%$ at 4 years after initial stent implantation. Complications were rare, tolerance was excellent, and, most important, the growth of the patients was maintained during followup. Compression of a coronary artery is a potential problem when one is enlarging the native outflow tract (either by angioplasty or stenting), and this may also be an issue when one is enlarging a conduit with a stent, from posterior compression at the level of the right ventricular free wall. This should be considered if the original conduit was implanted because of an anomalous vessel and the stent would traverse the free wall. In this series, we did not encounter this constellation, but it should be addressed with selective coronary angiography or test balloon dilation with electrocardiographic monitoring, or both, if the anatomic situation exists. ${ }^{19}$ Stent fractures, reported by Powell and associates, ${ }^{8}$ were not observed, but may develop as a result of compression by the sternum on an anteriorly placed conduit and the ventricular mass.

Limitations to more widespread applications, ${ }^{18,20,21}$ especially in small children, remain the requirement for the use of large sheaths to introduce the stents and the use of small stents limited by patient growth. With improved balloon technology, smaller sheaths may now be used ${ }^{21,22}$ and repeat balloon dilation of implanted stents may be safely performed to deal with restenosis and patient growth. ${ }^{23,24}$ In our study, results of further transcatheter reintervention, including balloon dilation of the initially implanted stent and the implantation of additional stents, were less optimal, with good clinical results achieved in only 8 of 15 patients. This is, in part, related to the observation that restenosis after initial stent implantation is more often caused by the presence of small conduits, relative to patient growth, than by a discrete restenosis. In such situations, where there is no discrete restenosis within the stented conduit, or no newly acquired obstruction, we would therefore recommend proceeding with surgical replacement rather than re-dilation, using conventional criteria for reintervention. Additionally, when surgery did occur on these stented implants, replacement was not associated with any technical surgical problem. The stents were cut across with heavy scissors, and the conduits were opened and removed by conventional approaches. Stents that were placed into pulmonary arteries were similarly addressed, frequently cut longitudinally and patched. ${ }^{25}$

Placement of stents across valved conduits causes free pulmonary valve insufficiency. This can be further aggravated by more distal obstruction, emphasizing the importance of assessing the pulmonary flow run-off and treating distal branch stenosis, if present, before stent implantation. The long-term effect of free pulmonary insufficiency on right ventricular function is a concern. What is gained by the reduction of stress on the right ventricular myocardium as a result of the relief of the outflow obstruction could be lost by increased stress induced by pulmonary insufficiency in the long-term, as seen in the adult with repaired Fallot's tetralogy. However, this form of conduit "rejuvenation" is not intended as a long-term solution, but as a medium-term palliation to extend conduit life and avoid early reoperation. Frequently, associated with conduit obstruction, significant or "free" pulmonary insufficiency coexists. In such situations, the stent implant does not worsen the preexisting volume load lesion, but reduces the systolic component of potential myocardial dysfunction. Indeed, the development of volume overload right ventricular failure is rare during these relatively brief periods when the stent is used to postpone, but not eliminate, repeat surgery. In our study, free pulmonary insufficiency was clinically well tolerated, and 
analysis of the right ventricular dimensions, from Mmode echocardiography, and the cardiothoracic ratios, from chest radiographs, revealed no significant increase during follow-up.

In conclusion, our study confirms that transcatheter endovascular stent implantation in obstructed subpulmonary ventricle-to-pulmonary artery conduits is an effective and safe palliation. It should be offered to growing children who are seen with conduit obstruction, especially when the obstruction is caused by valvar or supravalvar stenosis. It allows postponement of surgical conduit replacement, with good clinical tolerance and without impairing patient growth.

\section{REFERENCES}

1. Razzouk AJ, Williams WG, Cleveland DC, et al. Surgical connections from ventricle to pulmonary artery. Comparison of four types of valved implants. Circulation 1992;86 [suppl II]:154-8.

2. Stark J, Bull C, Stajevic M, Jothi M, Elliott M, de Leval M. Fate of subpulmonary homograft conduits: determinants of late homograft failure. J Thorac Cardiovasc Surg 1998;115:506-16.

3. Salim MA, DiSessa TG, Alpert BS, Arheart KL, Novick WM, Watson DC. The fate of homograft conduits in children with congenital heart disease: an angiographic study. Ann Thorac Surg 1995;59:67-73.

4. Heinemann MK, Hanley FL, Fenton KN, Jonas RA, Mayer JE, Castaneda AR. Fate of small homograft conduits after early repair of truncus arteriosus. Ann Thorac Surg 1993;55:1409-12.

5. Cleveland DC, Williams WG, Razzouk AJ, et al. Failure of cryopreserved homograft valved conduits in the pulmonary circulation. Circulation 1992;86 [suppl II]:II-150-II-153.

6. Hayes AM, Nykanen DG, McCrindle BW, Smallhorn JF, Freedom RM. Use of balloon expandable stents in the palliative relief of obstructed right ventricular conduits. Cardiol Young 1997;7:423-33.

7. Hosking MCK, Benson LN, Nakanishi T, Burrows PE, Williams WG, Freedom RM. Intravascular stent prosthesis for right ventricular outflow obstruction. J Am Coll Cardiol 1992; 20:373-80.

8. Powell AJ, Lock JE, Keane JF, Perry SB. Prolongation of RV-PA conduit life span by percutaneous stent implantation. Intermediate-term results. Circulation 1995;92:3282-8.

9. Almagor Y, Prevosti LG, Bartorelli AL, et al. Balloon expandable stent implantation in stenotic right heart valved conduits. J Am Coll Cardiol 1990;16:1310-4.

10. Stark J, de Leval M. Surgery for congenital heart disease. New York: Grune and Stratton; 1985. p. 460.
11. Chan KC, Fyfe DA, McKay CA, Sade RM, Crawford FA. Right ventricular outflow reconstruction with cryopreserved homografts in pediatric patients: intermediate-term follow-up with serial echocardiographic assessment. J Am Coll Cardiol 1994;24: 483-9.

12. Canter CE, Gutierrez FR, Molina P, Hartmann AF, Spray TL. Noninvasive diagnosis of right-sided extracardiac conduit obstruction by combined magnetic resonance imaging and continuous-wave Doppler echocardiography. J Thorac Cardiovasc Surg 1991;101:724-31.

13. Teirstein PS, Yock PG, Popp RL. The accuracy of Doppler ultrasound measurement of pressure gradients across irregular, dual, and tunnellike obstructions to blood flow. Circulation 1985;72: 577-84.

14. Lloyd TR, Marvin WJ, Mahoney LT, Lauer RM. Balloon dilation valvuloplasty of bioprosthetic valves in extracardiac conduits. Am Heart J 1987;114:268-74.

15. Waldman JD, Schoen FJ, Kirkpatrick SE, Mathewson JW, George L, Lamberti JJ. Balloon dilatation of porcine bioprosthetic valves in the pulmonary position. Circulation 1987;76:109-14.

16. Zeevi B, Keane JF, Perry SB, Lock JE. Balloon dilation of postoperative right ventricular outflow obstructions. J Am Coll Cardiol 1989;14:401-8.

17. Ritter SB. Balloon dilation: recession or inflation? J Am Coll Cardiol 1989;14:409-12.

18. O'Laughlin MP, Slack MC, Grifka RG, Perry SB, Lock JE, Mullins CE. Implantation and intermediate-term follow-up of stents in congenital heart disease. Circulation 1993;88:605-14.

19. Maheshwari S, Bruckheimer E, Nehgme RA, Fahey JT, Kholwadwala D, Hellenbrand WE. Single coronary artery complicating stent implantation for homograft stenosis in tetralogy of Fallot. Cathet Cardiovasc Diagn 1997;42:405-7.

20. Benson LN, Nykanen D, Freedom RM. Endovascular stents in congenital heart disease. Prog Cardiovasc Dis 1996;39:165-86.

21. Shaffer KM, Mullins CE, Grifka RG, et al. Intravascular stents in congenital heart disease: short- and long-term results from a large single-center experience. J Am Coll Cardiol 1998;31:661-7.

22. Hatai Y, Nykanen DG, Williams WG, Freedom RM, Benson LN. Endovascular stents in children under 1 year of age: acute impact and late results. Br Heart J 1995;74:689-95.

23. Ing FF, Grifka RG, Nihill MR, Mullins CE. Repeat dilation of intravascular stents in congenital heart defects. Circulation 1995;92:893-7.

24. Morrow WR, Palmaz JC, Tio FO, Ehler WJ, vanDellen AF, Mullins CE. Re-expansion of balloon-expandable stents after growth. J Am Coll Cardiol 1993;22:2007-13.

25. Coles JG, Yemets I, Najm HK, Lukanich JM, Perron J, Wilson GJ, et al. Experience with repair of congenital heart defects using adjunctive endovascular devices. J Thorac Cardiovasc Surg 1995;110:1513-9. 